\title{
Implementation of Black Box Models for Internal Ballistics Optimization Using an Artificial Neural Network
}

\author{
Jie Chen, ${ }^{1}$ JingYin Li ${ }^{D},{ }^{1}$ ShuangXi Li, ${ }^{2}$ and YunXiang You ${ }^{3}$ \\ ${ }^{1}$ Department of Fluid Machinery and Engineering, School of Energy and Power Engineering, Xian Jiaotong University, China \\ ${ }^{2}$ Laboratory of Fluid Seal, Beijing University of Chemical Technology, China \\ ${ }^{3}$ State Key Laboratory of Ocean Engineering, Shanghai Jiao Tong University, China \\ Correspondence should be addressed to JingYin Li; jyli@mail.xjtu.edu.cn
}

Received 27 July 2018; Revised 9 September 2018; Accepted 11 September 2018; Published 15 October 2018

Academic Editor: Guang-Yong Sun

Copyright (@) 2018 Jie Chen et al. This is an open access article distributed under the Creative Commons Attribution License, which permits unrestricted use, distribution, and reproduction in any medium, provided the original work is properly cited.

\begin{abstract}
The process of UUV delivery is a typical nonlinear transient dynamic phenomenon, which is generally described by the internal ballistic model. Evaluation of optimal internal ballistics parameters is a key step for promoting ballistic weapon performance under given launch constraints. Hence, accurate and efficient optimization techniques are required in ballistics technology. In this study, an artificial neural network (ANN) is used to simplify the process of regression analysis. To this end, an internal ballistics model is built in this study as a black box for a classic underwater launching system, such as a torpedo launcher, based on ANN parameter identification. The established black box models are mainly employed to calculate the velocity of a ballistic body and the torque of a launching pump. Typical internal ballistics test data are adopted as samples for training the ANN. Comparative results demonstrate that the developed black box models can accurately reflect changes in internal ballistics parameters according to rotational speed variations. Therefore, the proposed approach can be fruitfully applied to the task of internal ballistics optimization. The optimization of internal ballistics precision control, optimal control of the launching pump, and optimal low-energy launch control were, respectively, realized in conjunction with the established model using the SHERPA search algorithm. The results demonstrate that the optimized internal ballistics rotational speed curve can achieve the optimization objectives of low-energy launch and peak power while meeting the requirements of optimization constraints.
\end{abstract}

\section{Introduction}

UUV (unmanned underwater vehicle) is widely used in deepsea exploration, survival risk such as underwater operation generally can be set in the water or underwater, the advantages of underwater release severe sea state can be avoided, but release of UUV underwater conditions needs to rely on the submarine weapon launch system to achieve. Air-turbine pump (ATP) launch system (Figure 1) is the navy submarine in active service in the world's most advanced hydraulic balance type deep-water launcher, large launch depth, small volume, light weight, strong commonality, high emission energy utilization, and low-noise emission, suitable for equipment of submarine [1].

When UUV is projected, the launch pump accelerates and decelerates instantaneously, and the UUV movement is directly related to the pump's performance output. Therefore, the process of UUV delivery is a typical nonlinear transient dynamic phenomenon which is generally described by the internal ballistic model. The design of projectile UUV must meet strict muzzle velocity requirements while maintaining the safe launching of ballistic bodies. This process involves establishing internal ballistics parameters to meet performance requirements under particular launch constraints, such as the allowed internal maximum discharge pressure of launching tubes of a given length [2].

The overall design process therefore requires internal ballistics parameter optimization. However, conducting internal ballistics parameter optimization requires that an internal ballistics model first be established. Internal ballistics models seek to establish relationships between projectile weapon performance and weapon parameters and are frequently based on analytical expressions. Unfortunately, accurate analytical expressions can be quite difficult to obtain, particularly for 


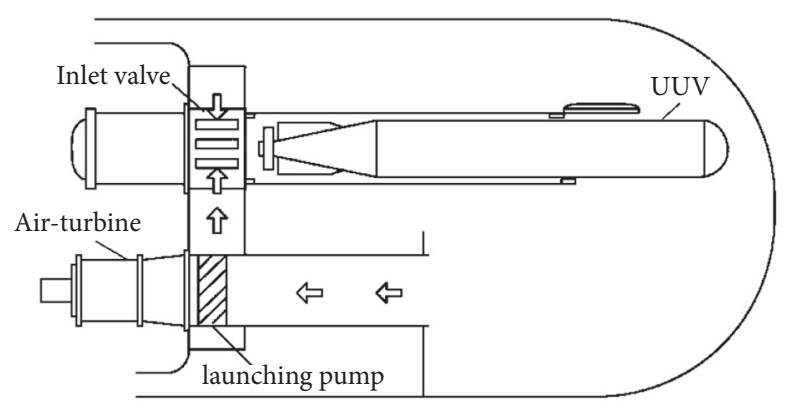

FIGURE 1: Schematic of ATP launch system [18].

the purposes of process control and parameter analysis. Meanwhile, in those cases where analytical expressions are obtainable, these expressions are often in the form of differential equations or partial differential equations for which exact solutions are difficult to obtain owing to the complexity of available numerical methods. In order to study the airturbine pump (ATP) launching system, the mathematical models are established for its main components, such as airbottle, launching valve, air-turbine, rotary pump, and so on. The simulation of the launching process is realized by the use of the simulation based on the program based on the mathematical models. The simulation result shows that the mathematical models are correct. These models can be used to analyze the performance characteristics of ATP launch system and be used in the design of this launching system.

From this point of view, the construction of internal ballistics models based on limited test data obtained in the process of weapon launching without solving complex differential equations is of substantial usefulness. This approach commonly involves regression analysis, which is a multifactor analysis method based on mathematical statistics and cybernetics that provides an analysis of the effect independent variables have on a dependent variable based on observed data points. The parameter expressions obtained using regression analysis for the launching process of ballistic bodies have demonstrated good precision [3]. The process of regression analysis is generally conducted as follows. (a) Determine the regression model and characteristic parameters. (b) Test the significance of the regression effect based on the regression coefficient. (c) Test the ability of the regression model to predict and control. (d) Select the optimal regression equation. While regression analysis can provide high precision, the analysis process is complex.

As an alternative to regression analysis, artificial neural networks (ANNs) are a reliable artificial intelligence approach that can also be utilized to identify significant internal ballistics parameters and construct internal ballistics models. ANNs, which mimic the human nervous system, represent a powerful approach for solving both regression and classification problems [4, 5]. In addition, there are many modeling methods for black box models, such as response surface methodology (RSM), artificial neural network (ANN), radial basis functions (RBF), Kriging (KRG), and so on. These modeling methods have been successfully applied to many optimization problems, such as structural optimization [6-9], etc. But compared with other methods, ANN have been successful applied for the nonlinear modeling of time series [10-13] which have the ability to modeling the complex nonlinear relationships among data, without any prior assumptions about the nature of such relationships[14]. The nonlinear characteristics, self-learning, and adaptive ability of the ANN approach impart a strong approximation capability for nonlinear mapping. Accordingly, this approach can be used to simulate the input-output relationships of a system accurately, and provide a reliable model of a nonlinear system with satisfactory precision. Moreover, ANNs need know nothing whatever about the relationships between the dependent variable and independent variables, which is in stark contrast to regression analysis. In addition, ANNs can also be applied for online identification, which is more effective for the real-time simulation analysis of systems. Finally, the successful application of ANNs in ballistic research has demonstrated its high capability and efficiency [15-17].

Therefore, ANNs represent a powerful and intelligent method for the identification of the parameters associated with an internal ballistics model with highly nonlinear characteristics.

In terms of parameters optimization, the most common methods currently employed for internal ballistics parameters optimization are mostly direct methods, such as the internal penalty function method, complex shape method, cutting plane method, feasible direction method, and switching technology. While the use of these methods for internal ballistics parameters optimization has been demonstrated to be feasible, direct methods have the two primary shortcomings of low computational efficiency and a tendency to fall into local optima [19]. Genetic algorithms (GAs) are stochastic optimization methods that have been widely used in the field of optimization [20-22] and have been gradually applied to internal ballistics parameter optimization. Because GAs employ probabilistic search, these algorithms incur no strict restrictions on the complexity of the model or objective function employed in the optimization process. These algorithms have also demonstrated good success with obtaining global optimum solutions without adopting constraints or employing gradient information in the objective function, and can converge relatively rapidly to global optimum solutions. However, GAs exhibit a relatively poor local search capability, such that a relatively large number of objective function calculations are required to locate global optimum solutions in the early stages of optimization [23]. Therefore, optimization methods employing a strictly GA approach are not ideal, and numerous GA-based hybrid optimization algorithms have been proposed. The SHERPA (i.e., simultaneous hybrid exploration that is robust, progressive, and adaptive) search algorithm is a particularly good example of a hybrid optimization algorithm that is characterized by hybrid capabilities and possesses an adaptive ability [24]. Its hybrid capabilities are embodied in its simultaneous (rather than sequential) use of multiple search methods, which provides numerous advantages, such as simultaneously conducting both global search and local search strategies. The adaptive ability is mainly embodied in the means by which the degree 
1. System identification

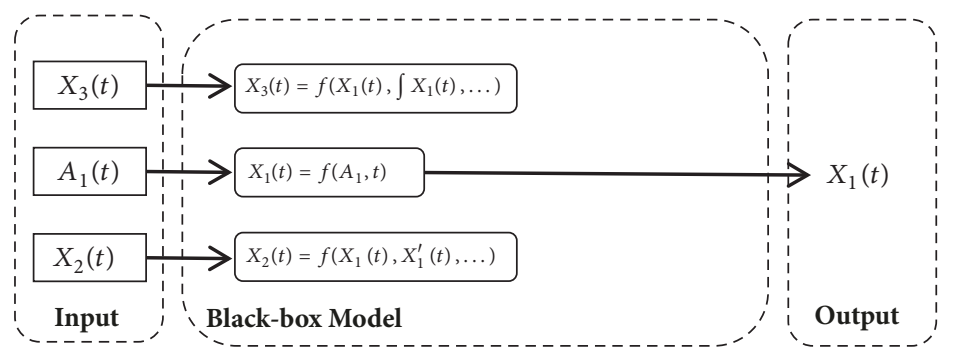

2. Model for simulation

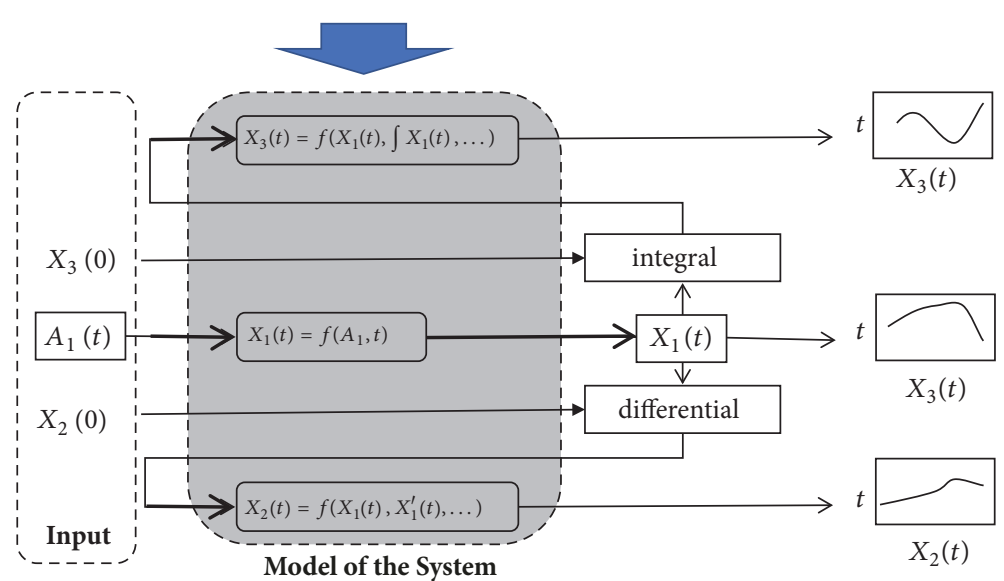

FIGURE 2: Schematic diagram of the description of a dynamic system using a black box model.

of participation of each search method is automatically adjusted according to the evolving knowledge of the search space, which is particularly suitable for complex problems. These features ensure that the SHERPA search algorithm generally has a higher efficiency than single search method algorithms or typical hybrid methods. Comparing with the benchmark results of different optimization algorithms (GA, SA, NLSQP, and RSM), it was shown to be far superior to the other algorithms in terms of both efficiency and robustness [24].

The characteristics of ANNs make them ideally suited for the construction of black box models, where internal ballistics are viewed merely as inputs and outputs without any knowledge of the internal workings of the model. The principle of a black box model is illustrated in Figure 2. The core idea of the black box model is to propose key controllable parameters $\left(A_{1}(t)\right)$, key state parameters $\left(X_{1}(t)\right)$, as well as the differential or integral variables $\left(X_{1}(t), X_{2}(t)\right)$ of the key state parameters, and to calculate the model relations of these parameters based on typical test data. Application of the black box model requires only the input of controllable parameters and the initial values of state parameters to obtain the values of state quantities and variables of a dynamic system that change with time.

This study employs an ANN to simplify the process of regression analysis with the aim of identifying key internal ballistics parameters. In addition, an internal ballistics model is built as a black box for a classic underwater launching system, such as a torpedo launcher, based on the identified key parameters. Typical internal ballistics test data are adopted as samples for training the ANN. Low-noise launching pump conditions have become a research subject of increasing interest. Under these conditions, the energy required for launch and the peak power must be as low as possible while ensuring the required muzzle velocity. Therefore, the optimization objective for internal ballistics in the present study is to achieve safe launch under low-energy and low peak power conditions. As such, optimization is mainly conducted with respect to weapon muzzle velocity, energy consumption, and peak power. To realize different internal ballistics control requirements, the SHERPA search algorithm was employed to perform three optimization calculations, which realized the optimization of internal ballistics precision control, optimal control of the launching pump, and optimal low-energy launch control, respectively. The remainder of this report is organized as follows. Section 2 presents two black box models used in this study to calculate the velocity of a ballistics body and torque of the launching pump. Furthermore, the ANN architecture is presented in Section 2. The optimization procedure pursued in this study is presented in Section 3. Section 4 discusses the results obtained by the proposed intelligent optimization process. The main conclusions drawn from the work are presented in Section 5.

\section{Internal Ballistics Black Box Models}

Meeting the optimization objective for internal ballistics in the present study using single-variable output black box models required the development of two black box models, denoted as black box model $\mathrm{A}$ and black box model $\mathrm{B}$, to 


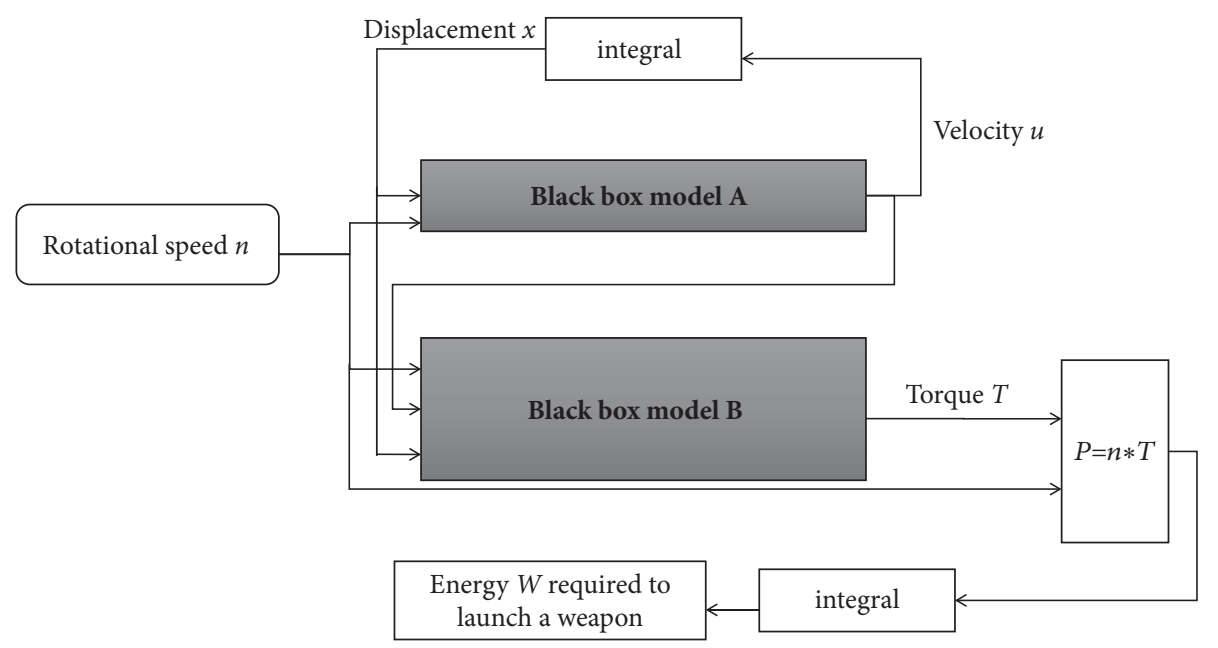

FIGURE 3: Internal ballistics model established in this study.

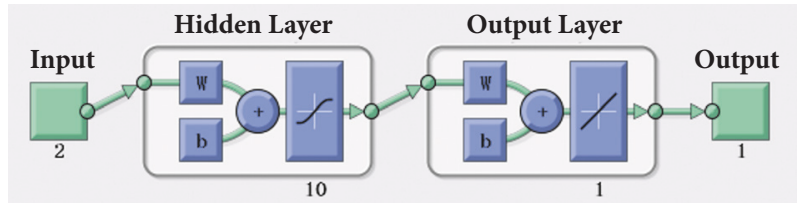

FIGURE 4: Neural network architecture of the developed black box models with an input layer of two neurons, a hidden layer of 10 neurons, and an output layer of a single neuron.

calculate the velocity of the ballistic body and the torque of the launching pump, respectively. The internal ballistics model shown in Figure 3 was established according to the developed black box models. For black box model A, the input was the experimentally determined rotational speed of the pump, the displacement of the ballistic body was taken as the state parameter, and the output was the ballistic body velocity. For black box model B, the input was the rotational speed curve, both the displacement and velocity of the ballistic body were taken as state parameters, and the output was the torque of the launching pump.

As illustrated in Figure 4, the ANN architecture of both models has three layers, including a single input layer with two neurons, a single output layer with only a single neuron, and a single hidden layer with 10 neurons. According to the data used to develop the ANN models, the numbers of neurons in the input and output layers are fixed, while the number of neurons in the hidden layer was optimized. The prediction results obtained the greatest accuracy for both the velocity of the ballistic body and the launching pump torque in black box models A and B, respectively, when 10 neurons were employed in the hidden layer.

To verify the black box models, internal ballistics test data for 12 data sets were compared with the velocity and torque results obtained from the black box models, including the learning samples. The comparative results obtained in this study are shown in Figure 5. As can be seen, the values obtained by the black box models developed in this study using the ANN approach are in good agreement with the experimental data.

In addition to average error (AE), other performance indicators, such as the mean absolute error (MAE), the root mean square error (RMSE), and the average absolute relative error (AARE), were determined to assess the model performances. Computed values for these performance indicators are listed in Table 1 . This verifies that black box models A and $\mathrm{B}$ can reflect changes in internal ballistics parameters according to rotational speed curve variations. Therefore, the models can be applied for the optimization of internal ballistics parameters.

\section{Optimization of Internal Ballistics Parameters}

During launching, the optimal control of internal ballistics can be realized by controlling the rotational speed of the launching pump. Therefore, the rotational speed curve was selected as the object of optimization, and the initial rotational speed curve was selected as a seven order polynomial: $n(t)=p_{1} t^{7}+p_{2} t^{6}+p_{3} t^{5}+p_{4} t^{4}+p_{5} t^{3}+p_{6} t^{2}+p_{7} t+p_{8}$, as shown in Figure 6.

Table 2 lists the input parameter settings employed for optimization, which are the time scaling factor (sct) and rotational speed scaling factor $(\mathrm{scn})$. Then, the rotational speed curve employed in the optimization calculation is $\mathrm{n}^{\prime}(\mathrm{t})$ $=n^{\prime}(t * s c t) * s c n$.

The objectives of optimization are (1) maximum muzzle velocity, (2) minimum peak power, and (3) minimum launch energy. According to the different requirements for the muzzle velocity and the launch power characteristics, a total of three groups of optimization calculations were conducted, including the optimization of internal ballistics precision control, optimal launch system load control, and optimal lowenergy launch control. 


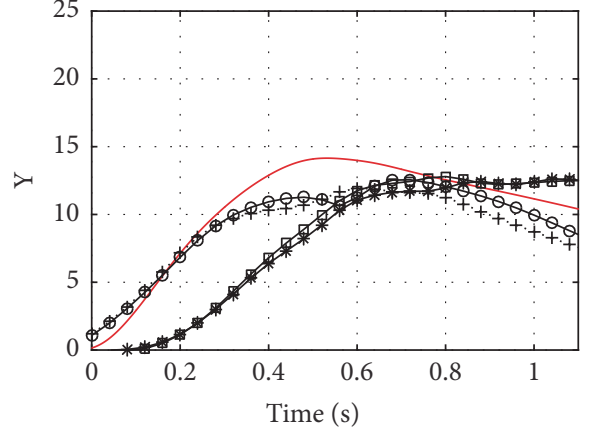

- $n$ (100rpm)-No.1

* $\operatorname{Exp} u(\mathrm{~m} / \mathrm{s})$

* Simulation $u(\mathrm{~m} / \mathrm{s})$

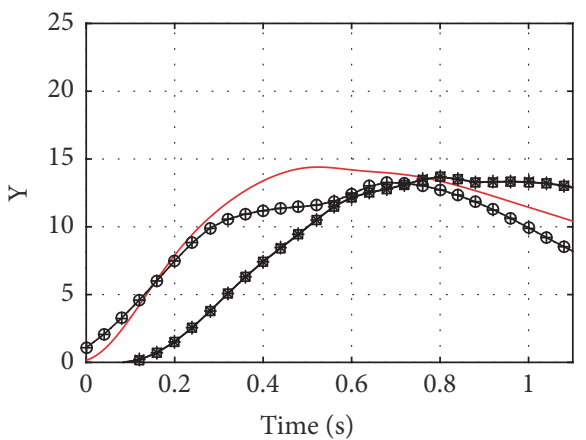

$-n$ (100rpm)-No.3 + $\operatorname{Exp} T(\mathrm{kNm})$

* $\operatorname{Exp} u(\mathrm{~m} / \mathrm{s}) \quad \odot$ Simulation $T(\mathrm{kNm})$

- Simulation $u(\mathrm{~m} / \mathrm{s})$

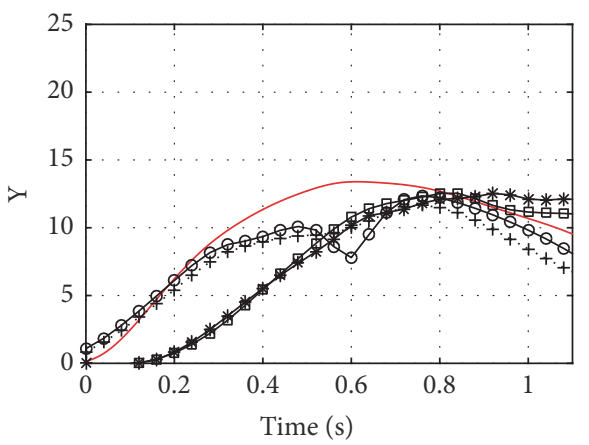

$-n$ (100rpm)-No.5 $+\operatorname{Exp} T(\mathrm{kNm})$

* $\operatorname{Exp} u(\mathrm{~m} / \mathrm{s})$

* Simulation $u(\mathrm{~m} / \mathrm{s})$

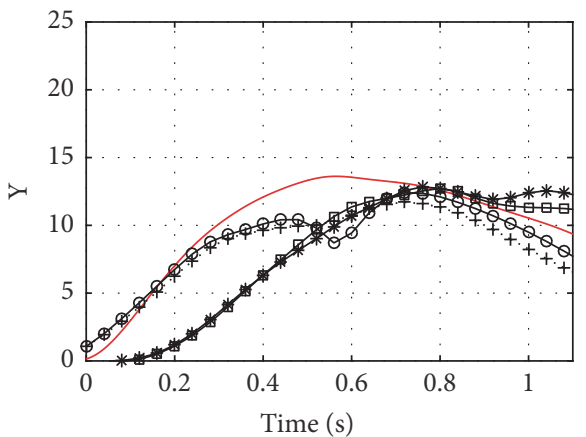

$-n$ (100rpm)-No.7 $+\operatorname{Exp} T(\mathrm{kNm})$

* $\operatorname{Exp} u(\mathrm{~m} / \mathrm{s})$

* Simulation $u(\mathrm{~m} / \mathrm{s})$

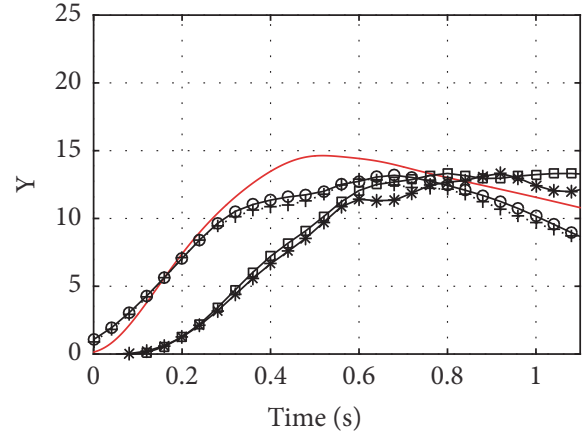

$-n(100 \mathrm{rpm})-\mathrm{No} .2+\operatorname{Exp} T(\mathrm{kNm})$

$* \operatorname{Exp} u(\mathrm{~m} / \mathrm{s})$
$\rightarrow$ Simulation $u(\mathrm{~m} / \mathrm{s})$

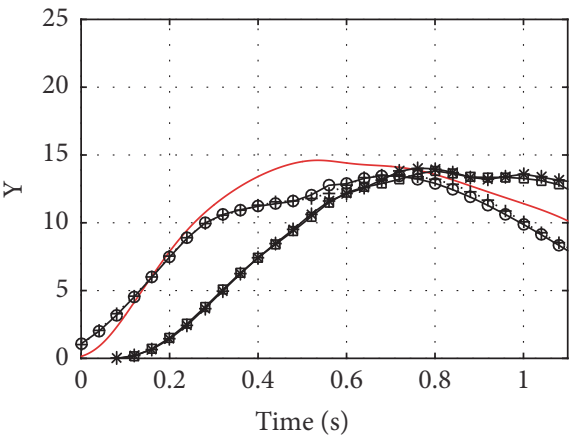

$-n$ (100rpm)-No.4 $+\operatorname{Exp} T(\mathrm{kNm})$

* $\operatorname{Exp} u(\mathrm{~m} / \mathrm{s})$

$\bullet$ Simulation $T(\mathrm{kNm})$

$\rightarrow$ Simulation $u(\mathrm{~m} / \mathrm{s})$

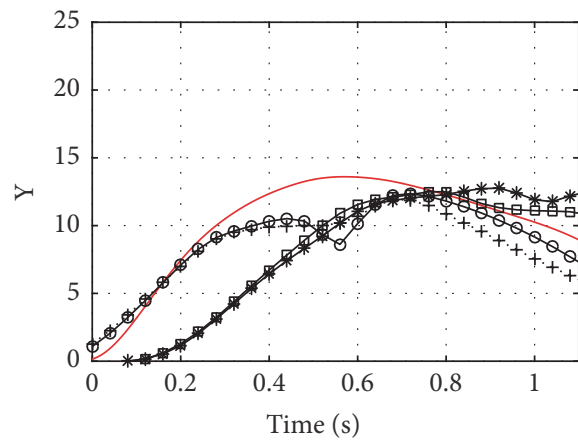

$-n$ (100rpm)-No.6 + $\operatorname{Exp} T(\mathrm{kNm})$

* $\operatorname{Exp} u(\mathrm{~m} / \mathrm{s})$

$\rightarrow$ Simulation $T(\mathrm{kNm})$

— Simulation $u(\mathrm{~m} / \mathrm{s})$

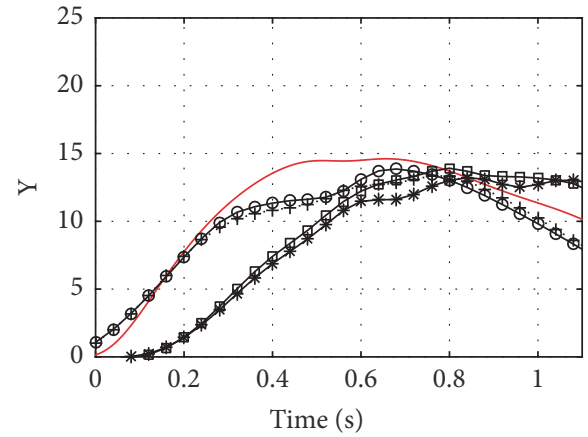

$-n$ (100rpm)-No. $+\quad+\operatorname{Exp} T(\mathrm{kNm})$

* $\operatorname{Exp} u(\mathrm{~m} / \mathrm{s})$

- Simulation $T(\mathrm{kNm})$

* Simulation $u(\mathrm{~m} / \mathrm{s})$

Figure 5: Continued. 


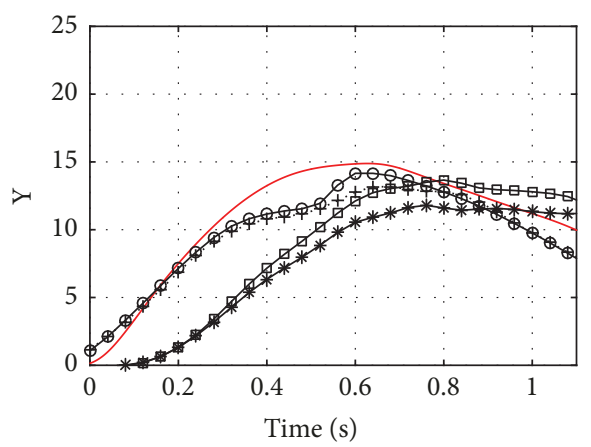

- $n$ (100rpm)-No.9

* $\operatorname{Exp} u(\mathrm{~m} / \mathrm{s})$

$\rightarrow$ Simulation $u(\mathrm{~m} / \mathrm{s})$

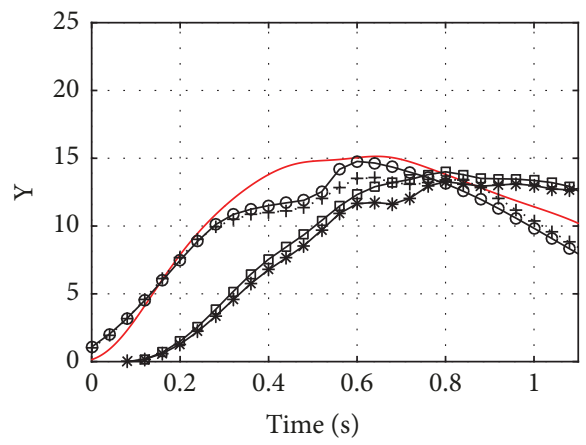

$-n$ (100rpm)-No.10 + $\operatorname{Exp} T(\mathrm{kNm})$

* $\operatorname{Exp} u(\mathrm{~m} / \mathrm{s}) \quad \rightarrow$ Simulation $T(\mathrm{kNm})$

— Simulation $u(\mathrm{~m} / \mathrm{s})$

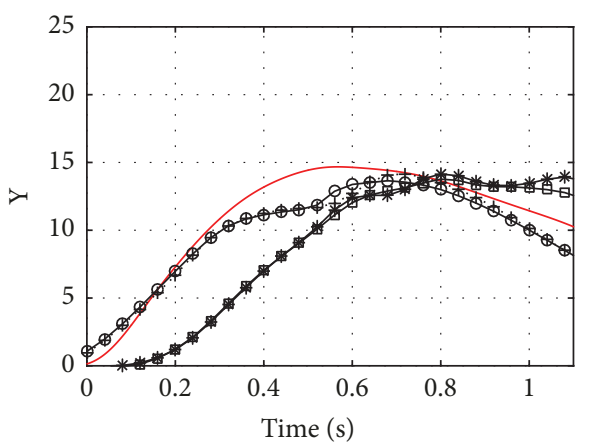

- $n$ (100rpm)-No.11

* $\operatorname{Exp} u(\mathrm{~m} / \mathrm{s})$

$+\operatorname{Exp} T(\mathrm{kNm})$

$\rightarrow$ Simulation $u(\mathrm{~m} / \mathrm{s})$

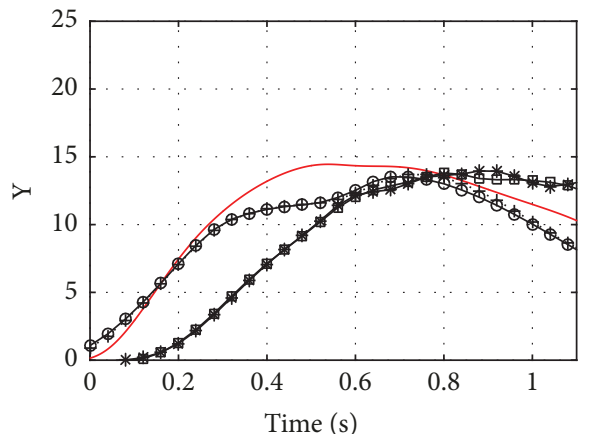

- $n(100 \mathrm{rpm})-\mathrm{No} 12$

* $\operatorname{Exp} u(\mathrm{~m} / \mathrm{s})$
$+\operatorname{Exp} T(\mathrm{kNm})$
+ Simulation $T(\mathrm{kNm})$

FIGURE 5: Comparison between test data and the results obtained using the black box models developed in this study.

TABLE 1: Overall error performance comparison using different performance indicators.

\begin{tabular}{|c|c|c|c|c|c|c|c|c|}
\hline \multirow[b]{2}{*}{ Indicators } & \multicolumn{4}{|c|}{ the ballistic body velocity: $\mathrm{u}(\mathrm{m} / \mathrm{s})$} & \multicolumn{4}{|c|}{ the torque of the launching pump: $\mathrm{T}(\mathrm{n} * \mathrm{~m})$} \\
\hline & $\mathrm{AE}$ & MAE & RMSE & AARE & $\mathrm{AE}$ & MAE & RMSE & AARE \\
\hline No.1 & $-2.56 \mathrm{E}-03$ & $2.56 \mathrm{E}-03$ & $6.52 \mathrm{E}-01$ & $2.32 \mathrm{E}-02$ & $-2.22 \mathrm{E}+00$ & $2.22 \mathrm{E}+00$ & $8.30 \mathrm{E}+02$ & $4.03 \mathrm{E}-02$ \\
\hline No.2 & 3.37E-04 & 3.37E-04 & 7.62E-01 & $2.76 \mathrm{E}-03$ & $-5.88 \mathrm{E}-01$ & $5.88 \mathrm{E}-01$ & $3.72 \mathrm{E}+02$ & $9.48 \mathrm{E}-03$ \\
\hline No.3 & $-5.58 \mathrm{E}-05$ & $5.58 \mathrm{E}-05$ & $3.96 \mathrm{E}-02$ & $4.63 \mathrm{E}-04$ & $3.70 \mathrm{E}-01$ & $3.70 \mathrm{E}-01$ & $8.21 \mathrm{E}+01$ & $7.20 \mathrm{E}-03$ \\
\hline No.4 & $-9.15 \mathrm{E}-04$ & 9.15E-04 & 3.19E-01 & 7.80E-03 & $-1.23 \mathrm{E}+00$ & $1.23 \mathrm{E}+00$ & $3.27 \mathrm{E}+02$ & $2.83 \mathrm{E}-02$ \\
\hline No.5 & $-1.85 \mathrm{E}-03$ & $1.85 \mathrm{E}-03$ & 7.51E-01 & $1.62 \mathrm{E}-02$ & $-6.23 \mathrm{E}+00$ & $6.23 \mathrm{E}+00$ & $1.19 \mathrm{E}+03$ & $2.53 \mathrm{E}-01$ \\
\hline No.6 & $-2.09 \mathrm{E}-03$ & $2.09 \mathrm{E}-03$ & $5.85 \mathrm{E}-01$ & $1.85 \mathrm{E}-02$ & $-6.61 \mathrm{E}+00$ & $6.61 \mathrm{E}+00$ & $1.11 \mathrm{E}+03$ & $2.99 \mathrm{E}-01$ \\
\hline No.7 & $-5.55 \mathrm{E}-04$ & $5.55 \mathrm{E}-04$ & $5.82 \mathrm{E}-01$ & $4.67 \mathrm{E}-03$ & $-5.07 \mathrm{E}+00$ & $5.07 \mathrm{E}+00$ & $9.43 \mathrm{E}+02$ & $1.68 \mathrm{E}-01$ \\
\hline No. 8 & $-3.05 \mathrm{E}-04$ & $3.05 \mathrm{E}-04$ & $6.62 \mathrm{E}-01$ & $2.55 \mathrm{E}-03$ & $-7.63 \mathrm{E}-01$ & 7.63E-01 & $4.50 \mathrm{E}+02$ & $1.66 \mathrm{E}-02$ \\
\hline No.9 & $-6.30 \mathrm{E}-03$ & $6.30 \mathrm{E}-03$ & $1.47 \mathrm{E}+00$ & $6.59 \mathrm{E}-02$ & $-1.67 \mathrm{E}+00$ & $1.67 \mathrm{E}+00$ & $3.23 \mathrm{E}+02$ & $3.96 \mathrm{E}-02$ \\
\hline No.10 & $-4.35 \mathrm{E}-04$ & 4.35E-04 & $8.34 \mathrm{E}-01$ & $3.65 \mathrm{E}-03$ & $-5.44 \mathrm{E}-01$ & $5.44 \mathrm{E}-01$ & $5.50 \mathrm{E}+02$ & 1.19E-02 \\
\hline No.11 & $1.13 \mathrm{E}-04$ & $1.13 \mathrm{E}-04$ & $3.59 \mathrm{E}-01$ & 9.35E-04 & $-6.22 \mathrm{E}-01$ & $6.22 \mathrm{E}-01$ & $3.71 \mathrm{E}+02$ & $1.31 \mathrm{E}-02$ \\
\hline No.12 & $-6.57 \mathrm{E}-04$ & $6.57 \mathrm{E}-04$ & 3.01E-01 & $5.56 \mathrm{E}-03$ & $-7.88 \mathrm{E}-01$ & 7.88E-01 & $3.15 \mathrm{E}+02$ & $1.69 \mathrm{E}-02$ \\
\hline
\end{tabular}

TABLE 2: Input parameter settings employed in the optimization process.

\begin{tabular}{lccc}
\hline Variable & Initial value & Minimum & Maximum \\
\hline Time scaling factor $(s c t)$ & 1 & 0.75 & 1.5 \\
\hline Rotational speed scaling factor $(s c n)$ & 1 & 0.75 & 1.5 \\
\hline
\end{tabular}




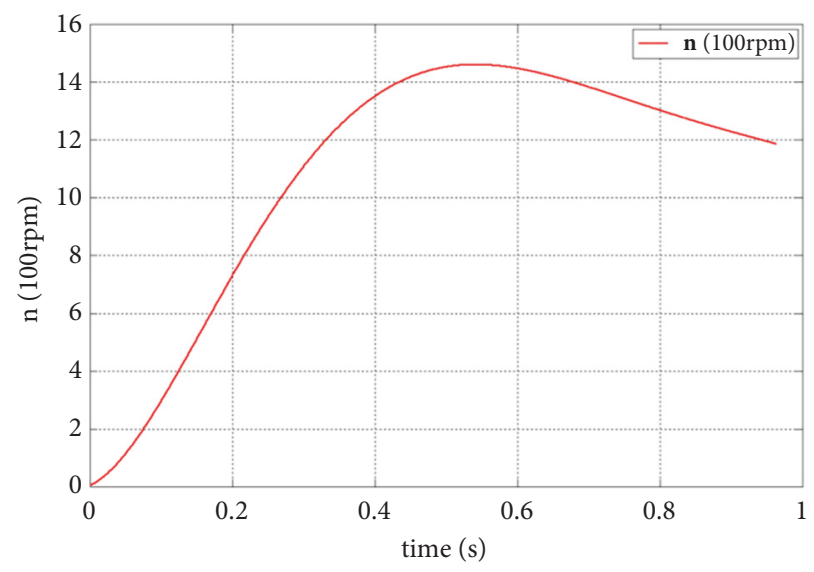

FIGURE 6: Rotational speed curve of the optimization process.

TABLE 3: Constraint conditions set for the control of internal ballistics.

\begin{tabular}{lcc}
\hline Variable & Constraints & Unit \\
\hline Muzzle velocity & $>14$ & $\mathrm{~m} / \mathrm{s}$ \\
\hline Peak power & $<4,000$ & $\mathrm{~kW}$ \\
\hline Power growth rate & $<6,000$ & $\mathrm{~kW} / \mathrm{s}$ \\
\hline
\end{tabular}

\section{Results and Discussion}

4.1. Optimization of Internal Ballistics Precision Control. Table 3 lists the constraint conditions set for optimization of the internal ballistics precision control using the developed model.

Moreover, the optimization process performed is illustrated in Figure 7 . The results obtained from the optimization process are summarized in Table 4.

Figure 8 shows the results of the optimum internal ballistics calculation. Here, the calculation is automatically stopped when the ballistics body exits the tube. Therefore, the final data point is the muzzle velocity.

4.2. Optimal Load Control of Launching Pump. When the load capacity of the launch system is limited, the power growth rate of the pump should be reduced. Table 5 lists the constraint conditions set for optimization of the launching pump control using the developed model.

The optimization results obtained are listed in Table 6 .

Figure 9 shows the results of the optimum internal ballistics calculation. The obtained results indicate that the power growth rate is significantly decreased by $28 \%$, considering a decrease in the muzzle velocity after the internal ballistics optimization.

4.3. Optimal Low-Energy Launch Control. When the launch energy is limited, it must be decreased. Correspondingly, the muzzle velocity should be reduced. Table 7 lists the constraint conditions set for optimization of the low-energy launch control using the developed model. Table 8 lists the optimization results obtained. The results demonstrate that the launch energy was reduced by $25 \%$. Furthermore, the power growth rate has been significantly reduced from $28 \%$ to $14 \%$ by decreasing the muzzle velocity from 13.96 to $10 \mathrm{~m} / \mathrm{s}$. Figure 10 shows the results of the optimum internal ballistics calculation.

\section{Conclusions}

This study aimed to develop a self-coupling black box model of a dynamic internal ballistics system based on the input of controllable parameters. Next, the developed model was employed for optimization to tune the internal ballistics parameters. The model was primarily employed to calculate the velocity of the ballistics body and the torque of the launching pump. The ANN method was applied for the parameter identification of the black box model. During model construction, typical internal ballistics test data were employed as samples for training the ANN. The results of comparative calculations demonstrated that the developed model can accurately reflect changes in internal ballistics parameters according to rotational speed variations. The SHERPA search algorithm was used for parameter optimization, and was applied for the optimization of internal ballistics precision control, optimal control of the launching pump, and optimal low-energy launch control, respectively. The results demonstrated that the optimized internal ballistics rotational speed curve can achieve the optimization objectives of lowenergy launch and peak power while meeting the requirements of optimization constraints. The internal ballistics optimization results also showed that the power growth rate was significantly reduced by a slight decrease in the muzzle velocity from 14 to $10 \mathrm{~m} / \mathrm{s}$. In addition, the launch energy decreased by $25 \%$ when the muzzle velocity was reduced.

\section{Data Availability}

The experiment data used to support the findings of this study have not been made available because the relevant data 


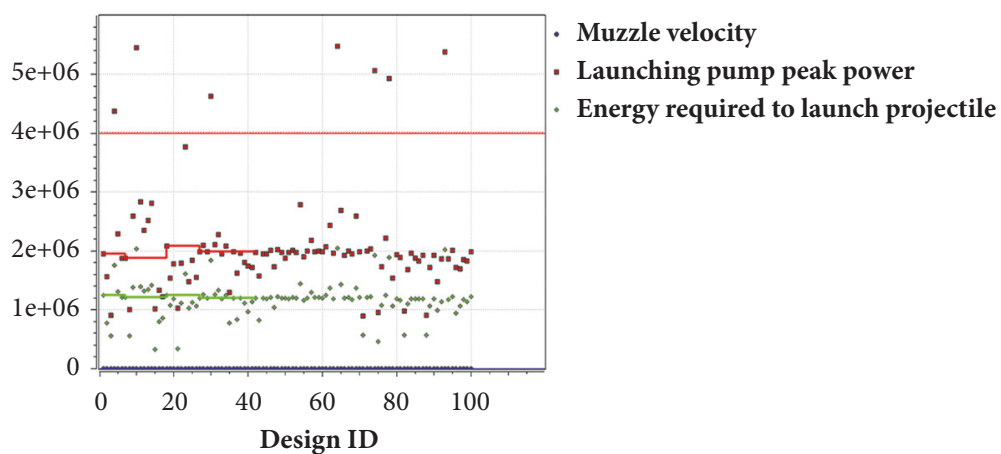

FIgURE 7: Optimization calculation process performed in this study.

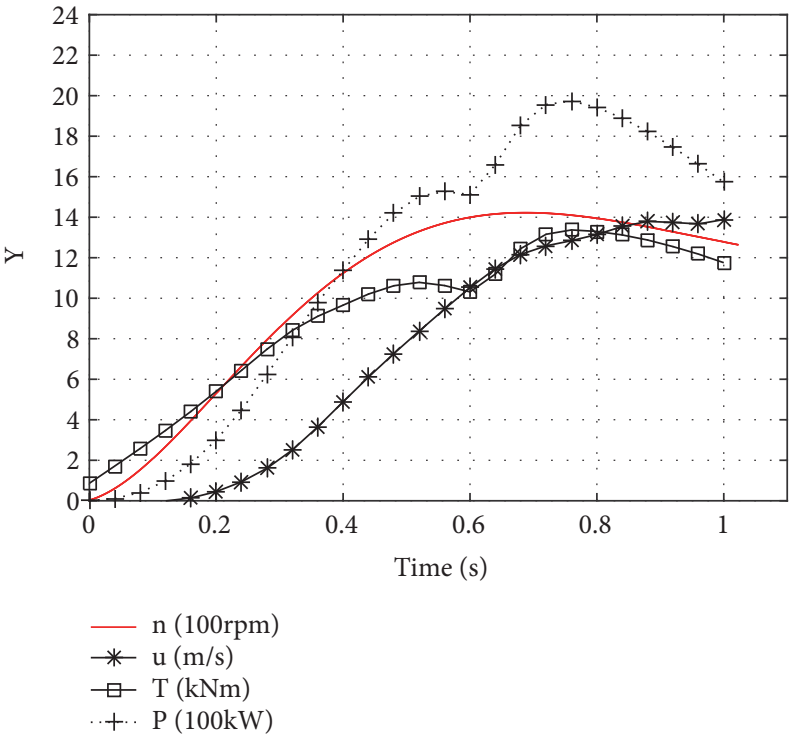

FIGURE 8: Results of the optimization calculation for the precision control of internal ballistics.

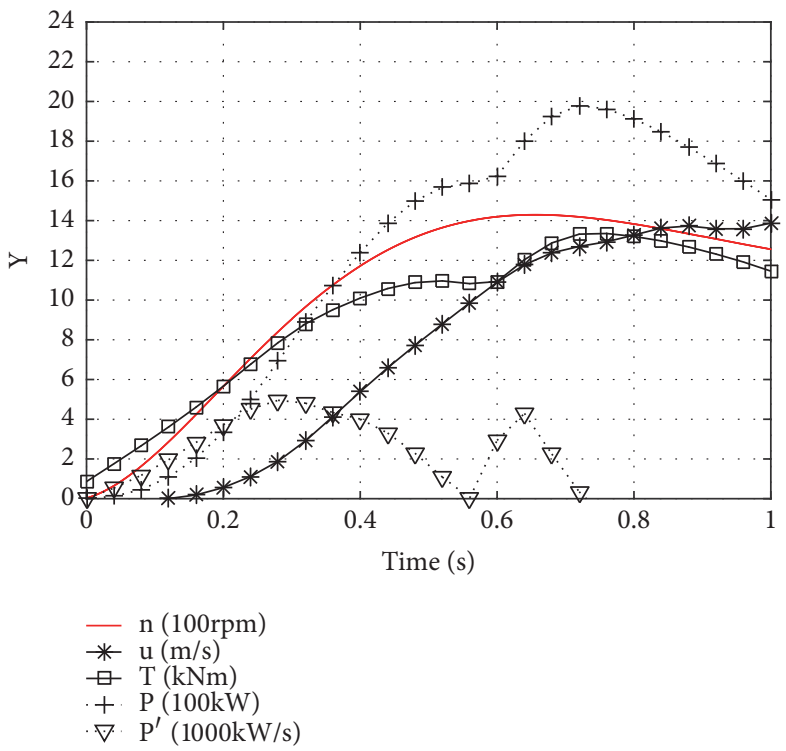

FIGURE 9: Results of the optimization calculation for the control of the launching pump. 
TABLE 4: Optimization results obtained for the control of internal ballistics.

\begin{tabular}{lccc}
\hline Variable & Unit & Optimization results & Difference compared with initial value \\
\hline$s c t$ & - & 0.788 & - \\
\hline$s c n$ & - & 0.975 & - \\
\hline Muzzle velocity & $\mathrm{m} / \mathrm{s}$ & 14.10 & $7 \%$ \\
\hline Peak power & $\mathrm{kW}$ & $1.98 \times 10^{3}$ & $2 \%$ \\
\hline Launch energy & $\mathrm{J}$ & $1.20 \times 10^{6}$ & $-3 \%$ \\
\hline Power growth rate & $\mathrm{kW} / \mathrm{s}$ & $5.85 \times 10^{3}$ & $-16 \%$ \\
\hline
\end{tabular}

TABLE 5: Constraint conditions set for the control of the launching pump.

\begin{tabular}{lcc}
\hline Variable & Constraints & Unit \\
\hline Muzzle velocity & $>14$ & $\mathrm{~m} / \mathrm{s}$ \\
Peak power & $<2,000$ & $\mathrm{~kW}$ \\
Power growth rate & $<5,000$ & $\mathrm{~kW} / \mathrm{s}$ \\
\hline
\end{tabular}

TABLE 6: Optimization results obtained for the control of the launching pump.

\begin{tabular}{lccc}
\hline Variable & Unit & Optimization results & Difference compared with initial value \\
\hline$s c t$ & - & 0.825 & - \\
$s c n$ & - & 0.98 & - \\
Muzzle velocity & $\mathrm{m} / \mathrm{s}$ & 13.96 & $6 \%$ \\
Peak power & $\mathrm{kW}$ & $1.98 \times 10^{3}$ & $2 \%$ \\
Launch energy & $\mathrm{J}$ & $1.21 \times 10^{6}$ & $-3 \%$ \\
Power growth rate & $\mathrm{kW} / \mathrm{s}$ & $4.98 \times 10^{3}$ & $-28 \%$ \\
\hline
\end{tabular}

TABLE 7: Constraint conditions set for low-energy launch control.

\begin{tabular}{lcc}
\hline Variable & Constraints & Unit \\
\hline Muzzle velocity & $>10$ & $\mathrm{~m} / \mathrm{s}$ \\
Peak power & $<2,000$ & $\mathrm{~kW}$ \\
Power growth rate & $<6,000$ & $\mathrm{~kW} / \mathrm{s}$ \\
\hline
\end{tabular}

TABLE 8: Optimization results obtained for low-energy launch control.

\begin{tabular}{lccc}
\hline Variable & Unit & Optimization results & Difference compared with initial value \\
\hline$s c t$ & - & 1.0875 & - \\
$s c n$ & - & 0.875 & - \\
Muzzle velocity & $\mathrm{m} / \mathrm{s}$ & 10.01 & $-24 \%$ \\
Peak power & $\mathrm{kW}$ & $1.36 \times 10^{3}$ & $-30 \%$ \\
Launch energy & $\mathrm{J}$ & $9.32 \times 10^{5}$ & $-25 \%$ \\
Power growth rate & $\mathrm{kW} / \mathrm{s}$ & $5.98 \times 10^{3}$ & $-14 \%$ \\
\hline
\end{tabular}




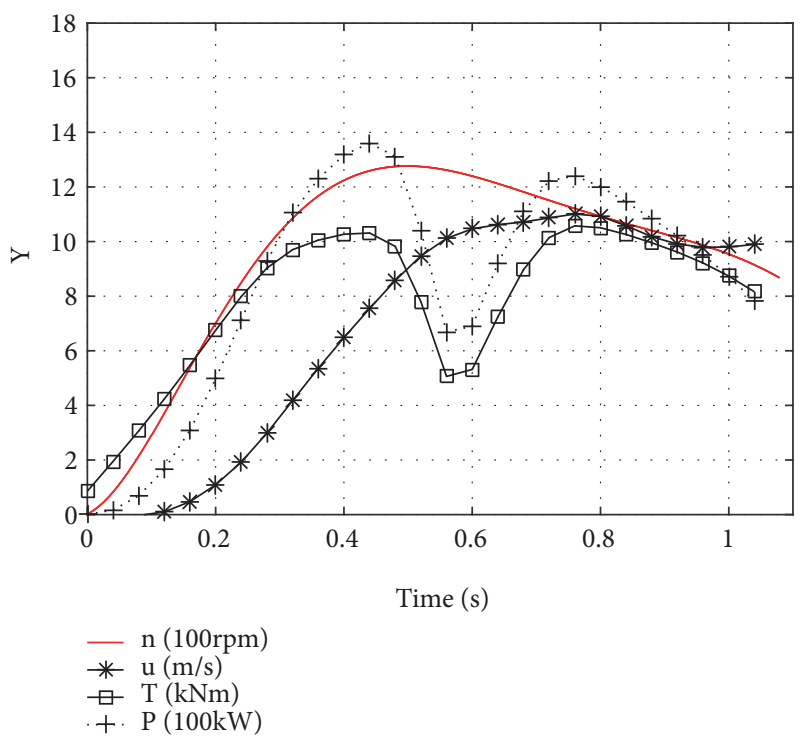

FIGURE 10: Results of the optimization calculation for low-energy launch control.

related to trade and technical secrets and other aspects of the content is not authorized by the relevant units to disclose.

\section{Disclosure}

As for the funding, the research involved in the manuscript has no relevant source of funds. Jie Chen is the presenting author.

\section{Conflicts of Interest}

The authors declare that they have no conflicts of interest.

\section{References}

[1] S.-Z. Wang and Y.-Z. Wang, Conspectus of naval ship-borne weapon equipment, The Publishing House of Ordnance Industry, Beijing, China, 1995.

[2] C. Yidiao and M. Shijie, Interior ballistics Calculation of Submarine Weapon Communication of Underwater UUV, vol. 3, pp. $1-18,1977$.

[3] D. Hao, Study on Parameters of Weapon Launching Process, UUV and Launching Technology, vol. 2, Palgrave Macmillan, 1999.

[4] A. Kamari, M. Nikookar, L. Sahranavard, and A. H. Mohammadi, "Efficient screening of enhanced oil recovery methods and predictive economic analysis," Neural Computing and Applications, vol. 25, no. 3-4, pp. 815-824, 2014.

[5] Y. Hajizadeh, "Intelligent prediction of reservoir fluid viscosity," in Proceedings of the Production and Operations Symposium, Society of Petroleum Engineers, Oklahoma City, Oklahoma, U.S.A., 2007.

[6] G. Y. Sun, G. Y. Li, Z. H. Gong, X. Y. Cui, X. J. Yang, and Q. $\mathrm{Li}$, "Multiobjective robust optimization method for drawbead design in sheet metal forming," Materials and Corrosion, vol. 31, no. 4, pp. 1917-1929, 2010.

[7] F. Xu, G. Sun, G. Li, and Q. Li, "Crashworthiness design of multicomponent tailor-welded blank (TWB) structures," Structural and Multidisciplinary Optimization, vol. 48, no. 3, pp. 653-667, 2013.

[8] J. Fang, Y. Gao, G. Sun, N. Qiu, and Q. Li, "On design of multicell tubes under axial and oblique impact loads," Thin-Walled Structures, vol. 95, pp. 115-126, 2015.

[9] J. Fang, G. Sun, N. Qiu, N. H. Kim, and Q. Li, "On design optimization for structural crashworthiness and its state of the art," Structural and Multidisciplinary Optimization, vol. 55, no. 3, pp. 1091-1119, 2017.

[10] C. L. Wu and K. W. Chau, "Data-driven models for monthly streamflow time series prediction," Engineering Applications of Artificial Intelligence, vol. 23, no. 8, pp. 1350-1367, 2010.

[11] T. A. Ferreira, G. C. Vasconcelos, and P. J. Adeodato, "A New Intelligent System Methodology for Time Series Forecasting with Artificial Neural Networks," Neural Processing Letters, vol. 28, no. 2, pp. 113-129, 2008.

[12] M. Bruen and J. Yang, "Combined hydraulic and black-box models for flood forecasting in urban drainage systems," Journal of Hydrologic Engineering, vol. 11, no. 6, pp. 589-596, 2006.

[13] V. Ramesh Kumar, "Pradipkumar Dixit, Artificial Neural Network Model for Hourly Peak Load Forecast," International Journal Of Energy Economics And Policy, vol. 8, no. 5, pp. 155$160,2018$.

[14] S. Ahmed, H. El Kadi, and A. AlSharif, "Three-dimensional Turbulent Swirling Flow Reconstruction Using Artificial Neural Networks," Journal of Mechanical Engineering and Automation, vol. 4, pp. 1-9, 2014.

[15] I. Gonzalez-Carrasco, A. Garcia-Crespo, B. Ruiz-Mezcua, and J. L. Lopez-Cuadrado, "Dealing with limited data in ballistic impact scenarios: an empirical comparison of different neural network approaches," Applied Intelligence, vol. 35, no. 1, pp. 89109, 2011.

[16] K.-J. Li and X.-B. Zhang, "Application of improved real-coded genetic algorithm in interior ballistic optimization," Journal of Ballistics, vol. 21, no. 3, pp. 19-22, 2009.

[17] C.-J. Liang, G.-L. Yang, and X.-F. Wang, "Structural dynamics optimization of gun based on neural networks and genetic algorithms," Acta Armamentarii, vol. 36, no. 5, pp. 789-794, 2015.

[18] Y.-Q. Lian, B. Tian, S.-Z. Wang, and Z.-H. Wu, "Simulation and analysis of the launching process of air-turbine pump launch system," Binggong Xuebao/Acta Armamentarii, vol. 32, no. 2, pp. 155-162, 2011.

[19] Z. Ming and S. Shudong, Genetic Algorithm Theory and Applications, National Defend Industry Press, Beijing, China, 1994.

[20] H. Chen, J.-S. Zhang, and C. Zhang, "Real-coded chaotic quantum-inspired genetic algorithm," Control and Decision, vol. 20, pp. 1300-1303, 2005.

[21] X.-D. Zhang, J.-P. Fu, and P.-L. Zhang, "Research on multiparameter according calculation of interior trajectory based on improved generic algorithm," Journal of Ballistics, vol. 18, no. 4, pp. 41-44, 2006.

[22] E. Mininno, F. Cupertino, and D. Naso, "Real-valued compact genetic algorithms for embedded microcontroller optimization," IEEE Transactions on Evolutionary Computation, vol. 12, no. 2, pp. 203-219, 2008.

[23] L. Zuyuan, F. Bowei, and Z. Chengsheng, Multidisciplinary decision optimization of ship hull form, National Defend Industry Press, Beijing, China, 2010.

[24] Red Cedar Technology, "SHERPA - An Efficient and Robust Optimization/Search Algorithm," 2017. 


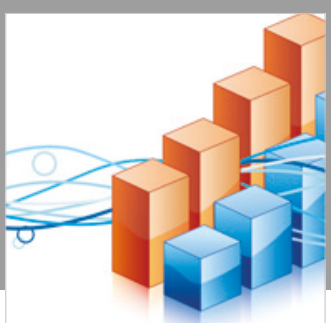

Advances in

Operations Research

\section{-n-m}
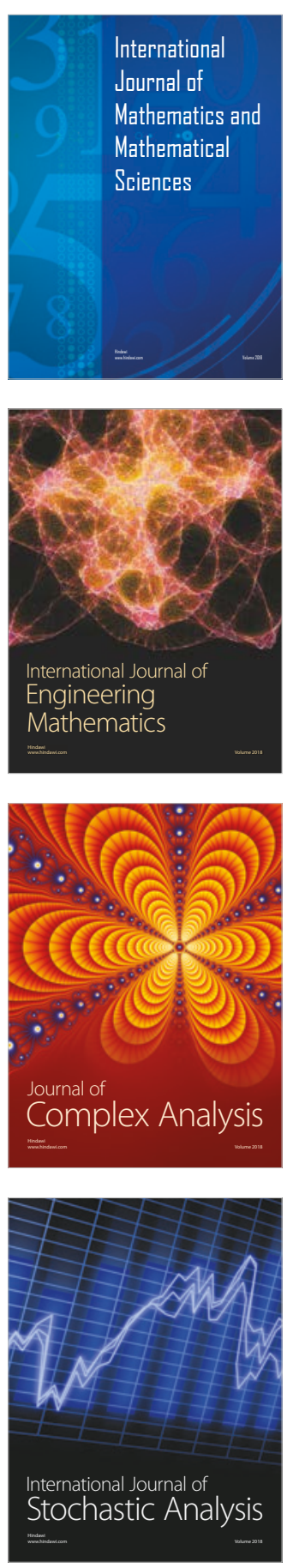
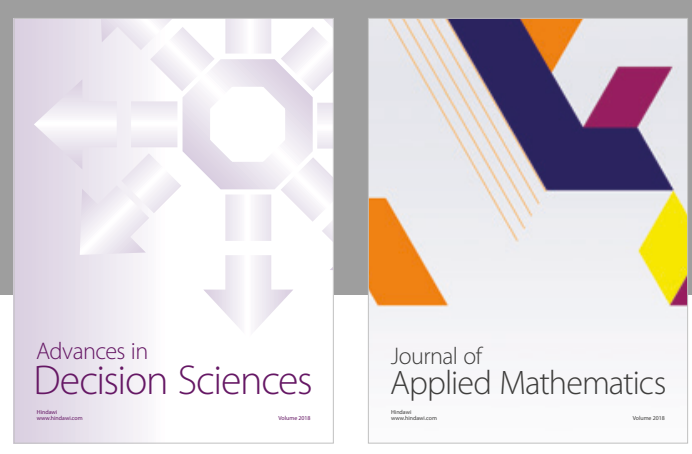

Journal of

Applied Mathematics
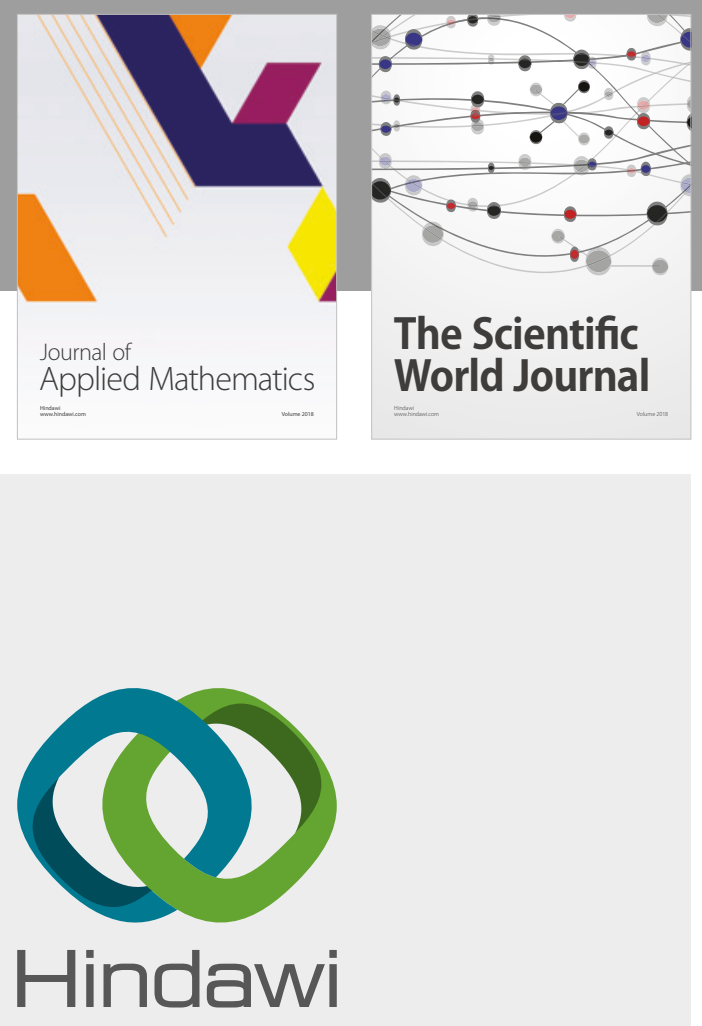

Submit your manuscripts at

www.hindawi.com

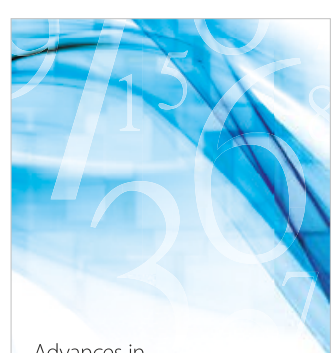

Advances in
Numerical Analysis
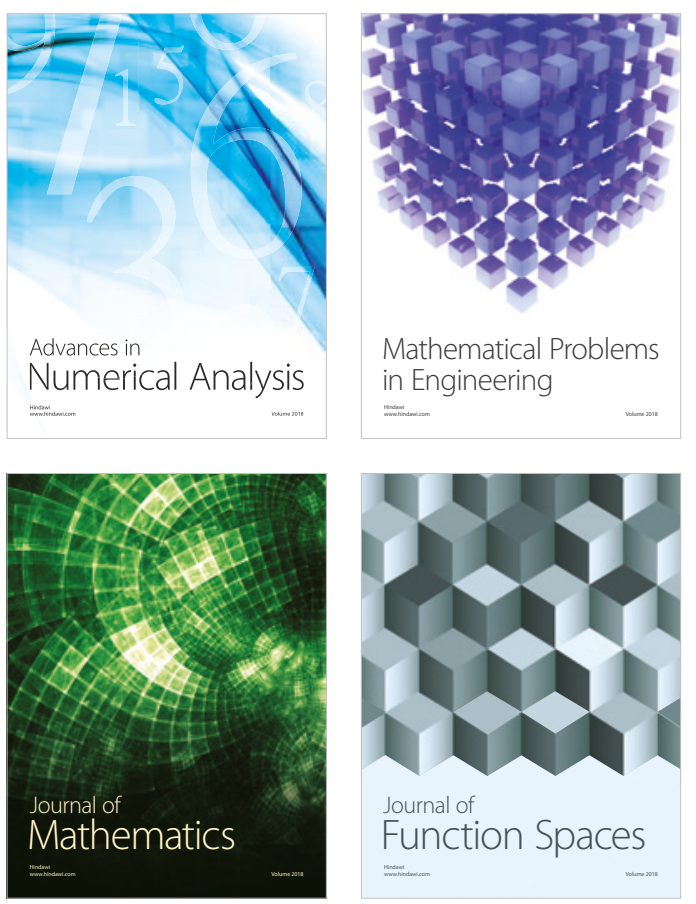

Mathematical Problems in Engineering

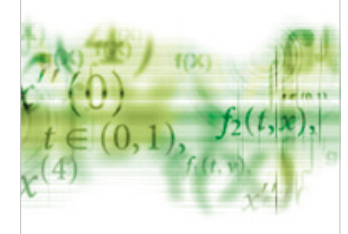

International Journal of

Differential Equations

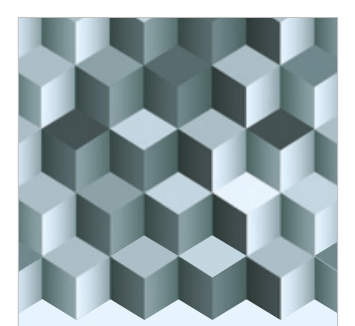

Journal of

Function Spaces

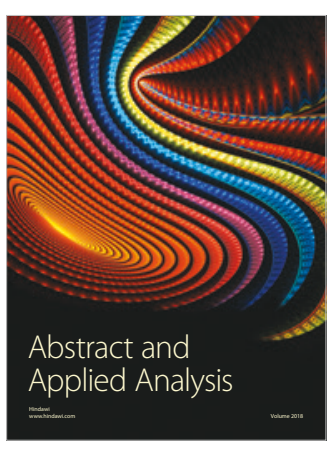

The Scientific

World Journal

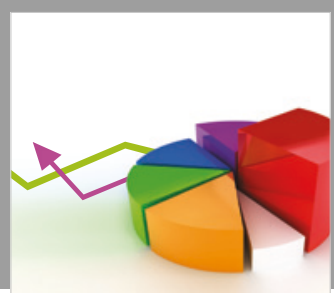

Journal of

Probability and Statistics
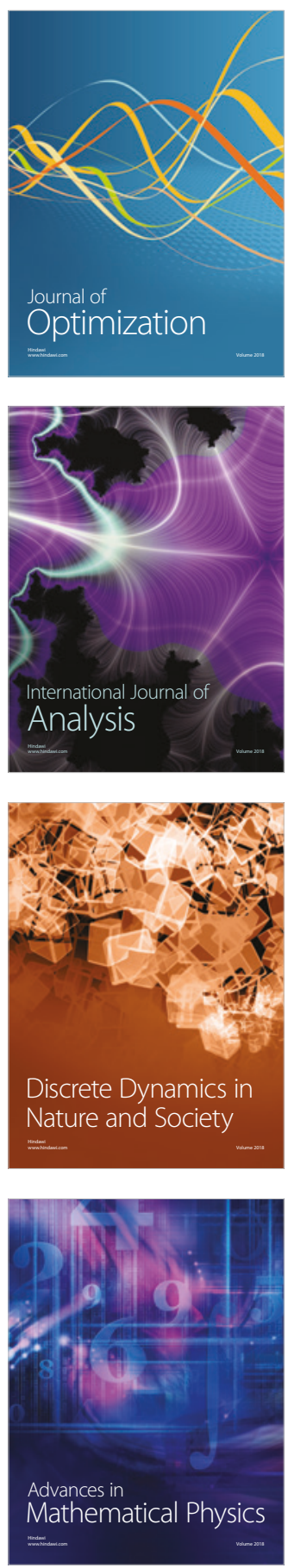